\title{
The Bree Problem with Different Yield Stresses On-Load and Off-Load and Application to Creep Ratcheting
}

\author{
by R.A.W.Bradford ${ }^{1}$, J.Ure ${ }^{2}$, H.F.Chen ${ }^{2}$ \\ ${ }^{1}$ EDF Energy, Barnett Way, Barnwood, Glos.GL4 3RS, UK, rick.bradford@edf-energy.com \\ ${ }^{2}$ Department of Mechanical \& Aerospace Engineering, University of Strathclyde, James Weir Building, 75 \\ Montrose Street, Glasgow G1 1XJ, UK
}

\begin{abstract}
The ratchet boundaries and ratchet strains are derived for the Bree problem and an elasticperfectly plastic material with different yield stresses on-load and off-load. The Bree problem consists of a constant uniaxial primary membrane stress and a cycling thermal bending stress. The ratchet problem with differing yield stresses is also solved for a modified loading in which both the primary membrane and thermal bending stresses cycle in-phase. The analytic solutions for the ratchet boundaries are compared with the results of deploying the linear matching method (LMM) and excellent agreement is found. Whilst these results are of potential utility for purely elastic-plastic behaviour, since yield stresses will often differ at the two ends of the cycle, the solution is also proposed as a means of assessing creep ratcheting via a creep ductility exhaustion approach.
\end{abstract}

\section{Keywords}

Ratcheting, Creep Ratcheting, Bree, Linear Matching Method, LMM

\section{Introduction}

The Bree problem, Refs.[1,2], addresses uniaxial ratcheting behaviour under a constant primary membrane stress, $\sigma_{p}$, plus a secondary wall-bending stress which cycles between zero and some maximum elastic value, $\sigma_{t}$. The secondary bending stress is strain controlled and is considered to be due to a uniform through-wall temperature gradient with the bending being fully restrained. Hence a net membrane strain might arise but the total bending strain is constrained to zero. Whilst the application that Bree had in mind in his original analyses, Refs.[1,2], was fast reactor fuel clad, and hence a cylindrical geometry, he analysed the problem as if for uniaxial stressing. Consequently the problem may be considered as relating to a beam of rectangular section.

A modified Bree problem consists of considering the primary membrane load to also cycle, in-phase with the thermal load. For an elastic-perfectly plastic material, the Bree and modified Bree problems are analytically tractable. On a plot of $\sigma_{t}$ against $\sigma_{p}$, simple analytic expressions can be derived for the boundaries of the regions producing ratcheting. Within these regions expressions can be derived for the ratchet strain per cycle. The case with cycling primary load was first discussed by $\mathrm{Ng}$ and Moreton, Refs.[3,4], and more recently by Bradford, Ref.[5].

The solutions of Refs.[1-5] all assume the same yield stress at all times during the load cycle. Realistically, yield stresses will vary around the cycle, for example due to temperature dependence. In this paper the ratchet boundaries and ratchet strains are derived for both the Bree and modified Bree problems but assuming different yield stresses on-load and off-load. For this purpose "on-load" is identified as being when the thermal load is acting whereas "off-load" is when there is no thermal load. The yield stress off-load, $\sigma_{y}^{p}$, is assumed to be greater than or equal to the yield stress onload, $\sigma_{y}^{c}$. The problem is analytically tractable in the same manner as Refs.[1-5]. Ratcheting problems which admit analytical solutions are scarce, and hence valuable. More commonly some form of numerical technique is used to solve ratcheting problems, particularly for applications to real structures. The use of finite element analysis with direct cyclic analysis methods, Ref.[6], can calculate the stabilised steady-state response of structures with far less computational effort than full step-by-step analysis. A technique which has been gaining ground in this respect is the Linear Matching Method (LMM), Refs.[7-10]. LMM is distinguished from other simplified methods in ensuring that both equilibrium and compatibility are satisfied at each stage. It can also accommodate temperature dependent yield stress, Ref.[11]. The method has been used here to confirm the analytic solutions for the ratchet boundaries for both the Bree and modified Bree loadings with distinct on-load and off-load yield stresses. 
In the creep regime, ratcheting may be due to a combination of creep and plastic strains. It is common practice in design codes and assessment procedures to assess plastic ratcheting and creep ratcheting separately. For example, the avoidance of plastic ratcheting is assured in R5, Ref.[12], by a shakedown assessment for which the acceptable limit is based on an appropriately factored tensile proof strength. In contrast, the avoidance of excessive accumulation of creep ratchet strains is assessed by a distinct step in the R5, Ref.[12], procedure, where it is referred to as "cyclically enhanced creep". The methodology for the cyclically enhanced creep assessment requires the identification of a "core stress", representative of the elastic core of the section. This core stress is entered into a suitable creep rupture expression to determine the operating time at which creep ratcheting may become a concern. This approach to assessing creep ratcheting is exemplified by the work of O'Donnell and Porowski, Ref.[13], and similar procedures to that of R5 can be found in ASME III NH, Ref.[14]. It is important to recall that this type of assessment against excessive creep ratcheting is valid only if the various other steps in the codes/procedures are correctly applied. In particular the structure must also be within certain primary stress and stress range limits and also pass the tests for plastic shakedown and creep rupture.

If attention were confined to elastic-plastic behaviour, the duration of the loading conditions would be of no consequence. Hence, in deriving purely plastic ratchet conditions it does not matter whether the thermal load is a short duration transient condition or is sustained during the on-load steady operating condition. In contrast, the duration of the loading becomes important if creep is significant. The core stress derived by O'Donnell and Porowski, Ref.[13], and adopted in R5, Ref.[12], refers to the condition after the thermal load has been removed, i.e., it assumes that the thermal load is a transient condition and is not acting during the creep dwell in steady operation. This paper proposes an alternative approach to the assessment of creep ratcheting which is applicable when the thermal load is sustained during steady on-load operation. For this purpose, the effective "yield" stress when onload, $\sigma_{y}^{c}$, is reinterpreted as the stress giving $0.2 \%$ inelastic strain on the isochronous creep curve at the operating temperature and over a single operating dwell. The ratcheting analysis provides separately the creep and plastic ratchet strains per cycle. Rather than using a core stress together with a creep rupture formulation, an assessment criterion can then be defined via an acceptable creep ratchet strain based on the creep ductility of the material.

\section{Analysis: Bree Loading}

Elastic-perfectly plastic behaviour is assumed with differing effective yield stresses on-load $\left(\sigma_{y}^{c}\right)$ and off-load $\left(\sigma_{y}^{p}\right)$ as shown by Fig.1. Young's modulus, $E$, is assumed constant. If there is no creep then $\sigma_{y}^{c}$ and $\sigma_{y}^{p}$ are simply the $0.2 \%$ proof stresses under the on-load and off-load conditions respectively (possibly multiplied by some shakedown factor, $K_{S}$ ). If creep is included then the thermal load is taken to be a steady load, sustained during operation in the creep regime. The on-load effective "yield" stress, $\sigma_{y}^{c}$, is then reinterpreted as the stress giving $0.2 \%$ inelastic strain on the isochronous creep curve at the operating temperature and over a single operating dwell (again possibly multiplied by some shakedown factor, $K_{S}$ ). The other yield stress, $\sigma_{y}^{p}$, is also reinterpreted as the smallest $0.2 \%$ proof stress $\left(\times K_{S}\right)$ at temperatures between the off-load and on-load conditions. Hence the two "yield" stresses, $\sigma_{y}^{c}$ and $\sigma_{y}^{p}$, can be aligned with creep and plastic behaviour. For either interpretation the ratio of the two effective "yield" strengths is defined,

$$
\alpha=\frac{\sigma_{y}^{c}}{\sigma_{y}^{p}} \leq 1
$$

The wall thickness is $t$ and the through-wall coordinate, $x$, varies from $-t / 2$ on one surface to $+t / 2$ on the other. The tensile side of bending on-load is taken as $x>0$. Calculation of the ratchet boundary and the ratchet strains proceeds exactly as for other Bree-type analyses, Refs.[1-5], the sole difference being the differing yield strengths at the two ends of the loading cycle. Note that the yield strength is assumed to be uniform through the thickness of the plate at all times. (Since there may be a temperature gradient across the wall, this is necessarily an approximation).

The key equations for Bree loading are, 
Operating:

$$
E \varepsilon=\sigma+E \varepsilon_{p}-\frac{2 \sigma_{t}}{t} x
$$

Shutdown:

$$
E \varepsilon=\sigma+E \varepsilon_{p}
$$

Equilibrium:

$$
\int_{-t / 2}^{+t / 2} \sigma \cdot d x=t \sigma_{p}
$$

Eq.(2) expresses the total strain as the sum of the elastic strain, the inelastic strain $\left(\varepsilon_{p}\right)$ and the thermal strain. In general, the inelastic strain is the sum of the plastic and creep strains.

The secondary bending is envisaged as arising from a through-wall temperature gradient. To generate the stress, the bending of the section is considered as restrained. Hence the total strain, $\varepsilon$, as given by Eq.(2), must be uniform through the wall. Eq.(3) is the corresponding requirement when shut down, when the temperature gradient is removed. Eq.(4) requires the stress distribution across the wall to be in equilibrium with the applied primary membrane load. In Bree loading Eq.(4) applies both on-load and off-load, since the primary membrane stress is assumed non-cycling.

Ratcheting conditions can arise when yielding takes place on-load on one surface only (Fig.2) or on both surfaces (Fig.3). These Figures show the stress distribution through the wall both on-load and off-load. A third ratcheting case arises when the stress distribution takes the form of Fig. 2 when onload (yielding on one surface only) but takes the form of Fig. 3 when off-load (yielding on both surfaces). This will be referred to as "Fig.2/3". Various other qualitatively different distributions of stress and strain are possible which do not ratchet, but attention is confined here to the ratcheting cases. The three cases, Fig.2, Fig.3 and Fig.2/3, cover all ratcheting conditions.

The requirement for ratcheting is that all parts of the section yield in tension under one or other of the two loading conditions. Hence, for ratcheting we require: for Fig.2: $a<b$; for Fig.3: $e<c$; for Fig.2/3: $a<c$. Eqs.(2-4) suffice to find expressions for the dimensions $a, b, c, d, e, f$ in Figs.2,3 and hence the ratchet conditions and ratchet strains can be found. The usual dimensionless loads $X$ and $Y$ are defined using the off-load (or plastic) yield strength, $\sigma_{y}^{p}$,

$$
X=\frac{\sigma_{p}}{\sigma_{y}^{p}}, \quad Y=\frac{\sigma_{t}}{\sigma_{y}^{p}}
$$

For Fig.2 to be applicable it is required that $\sigma_{1}>-\sigma_{y}^{c}$ and $\sigma_{2}>-\sigma_{y}^{p}$. For Fig.2/3 to be applicable it is required only that $\sigma_{1}>-\sigma_{y}^{c}$. Hence the boundaries between the regions in which Fig.2, Fig.3 and Fig. $2 / 3$ are applicable are defined by $\sigma_{1}=-\sigma_{y}^{c}$ and $\sigma_{2}=-\sigma_{y}^{p}$ which can be written in terms of $X, Y$ as,

$$
\begin{array}{ll}
\sigma_{1}=-\sigma_{y}^{c} \text { gives the "Creep Hyperbola": } & Y(\alpha-X)=\alpha^{2} \\
\sigma_{2}=-\sigma_{y}^{p} \text { gives the "Plastic Hyperbola": } & Y(1-X)=1
\end{array}
$$

Since $\alpha<1$ the creep hyperbola lies above the plastic hyperbola on the $(X, Y)$ plot. Hence the ratcheting region of the $(X, Y)$ plot is divided into three sub-regions, as illustrated by Fig.4 for the case $\alpha=0.6$,

- $\quad$ Type 1 (Fig.2): Below both hyperbolae;

- $\quad$ Type 2 (Fig.3): Above both hyperbolae;

- $\quad$ Type 3 (Fig.2/3): Between the two hyperbolae.

As illustrated by Fig.4, each of these three regions is further divided into two regions, of type $\mathrm{R}$ and type CR. Ratcheting occurs above the lower boundary of regions CR. The total ratchet strain is,

Regions CR1 and R1:

$$
\frac{\varepsilon_{\text {ratchet }}^{\text {total }}}{\varepsilon_{y}}=2\{Y-\sqrt{Y(1-X)}-\sqrt{Y(\alpha-X)}\}
$$


Regions CR2 and R2:

$\frac{\varepsilon_{\text {ratchet }}^{\text {total }}}{\varepsilon_{y}}=\left(\frac{1+\alpha}{\alpha}\right)(X Y-\alpha)$

Regions CR3 and R3:

$$
\frac{\varepsilon_{\text {ratchet }}^{\text {total }}}{\varepsilon_{y}}=X Y+Y-1-2 \sqrt{Y(\alpha-X)}
$$

where the "yield strain" is defined as,

$$
\varepsilon_{y}=\frac{\sigma_{y}^{p}}{E}
$$

The ratchet boundary is defined by the above ratchet strains becoming zero and hence is,

$$
\begin{array}{ll}
\text { Lower boundary of CR1: } & Y=\{\sqrt{(1-X)}+\sqrt{(\alpha-X)}\}^{2} \\
\text { Lower boundary of CR2: } & X Y=\alpha
\end{array}
$$

The common point of intersection of the hyperbolae (6) and (7) and the ratchet boundaries (12) and (13) is $X=\frac{\alpha}{1+\alpha}, Y=1+\alpha$, and this defines the lowest point of region CR3 (see Fig.4).

For the interpretation without creep, the total ratchet strain, given by the relevant Eq.(8-10), is all plastic strain and the lower boundary of regions CR1/CR2 given by Eqs. $(12,13)$ is the plastic ratchet boundary and depends upon the ratio of the two plastic yield strengths, $\alpha$.

For the interpretation with creep we wish to distinguish between creep ratchet strains and plastic ratchet strains. This can be done by noting that the purely plastic ratchet strains and plastic ratchet boundaries are obtained from $(8,9,12,13)$ by putting $\alpha=1$. The result is consistent with the Bree analysis, Refs.[1,2], and the expressions are given explicitly in Tables 1 and 2, labelled "plastic ratchet strain" and "plastic ratchet boundary". The region above these plastic ratchet boundaries are denoted R1, R2, R3 on Fig.4. Consequently we can identify CR1, CR2, CR3 as the regions in which ratcheting is occurring but would not occur if the behaviour was purely plastic, i.e., with no creep. Consequently the whole of the ratchet strain given by (8-10) may be interpreted as creep ratchet strain in regions CR1, CR2, CR3. However, in regions R1, R2, R3 both plasticity and creep contribute to ratcheting. The plastic ratchet strain is known on the basis of the expressions with $\alpha$ set to unity, and hence the creep ratchet strains follow by subtracting this plastic ratchet strain from the total ratchet strain given by (8-10). Table 2 gives the resulting complete set of plastic and creep ratchet strains in all regions.

Fig.5 shows the ratchet boundaries and sub-regions for $\alpha$ values of $0.4,0.5,0.6,0.7,0.8$ and 0.9 , noting that the lower boundary of the R-regions (the plastic ratchet boundary) is the same in every case. Table 1 summarises the algebraic expressions for the various curves on Fig.5.

\section{Analysis: Modified Bree Loading}

The modification to the loading consists of considering the primary membrane load to cycle between zero off-load and its maximum value on-load, i.e., in-phase with the thermal load. The controlling equations are again (2-4) except that Eq.(4) now applies only on-load. Off-load the equilibrium condition becomes,

Off-Load:

$$
\int_{-t / 2}^{+t / 2} \sigma \cdot d x=0
$$

A stress distribution like Fig. 2 cannot apply for modified Bree loading because (14) requires that the stress distribution be anti-symmetric off-load. Hence Fig.2 is replaced by Fig.6. This is the case when yielding occurs on only one surface on-load. The case when yielding occurs on both surfaces both onload and off-load is again given qualitatively by Fig.3, except that we now must have $c=-d$ in order to obey (14). The same "creep hyperbola", (6), arises from the requirement $\sigma_{1}>-\sigma_{y}^{c}$ in Fig.6. Because the "plastic hyperbola", (7), does not enter the analysis at this stage, the total ratchet strain expression is the same in type 1 and type 3 regions, 
Regions CR1, R1, CR3 and R3:

$\frac{\varepsilon_{\text {ratchet }}^{\text {total }}}{\varepsilon_{y}}=Y-1-2 \sqrt{Y(\alpha-X)}$

Regions CR2 and R2:

$$
\frac{\varepsilon_{\text {ratchet }}^{\text {total }}}{\varepsilon_{y}}=\frac{X Y}{\alpha}-(1+\alpha)
$$

The corresponding ratchet boundaries are,

Lower boundary of CR1 and CR3: $\quad \alpha-X=\frac{1}{4 Y}(Y-1)^{2}$

Lower boundary of CR2:

$$
X Y=\alpha(\alpha+1)
$$

For the interpretation without creep, the total ratchet strain, given by Eq.(15) or Eq.(16), is all plastic strain and the lower boundary of regions CR1/CR2/CR3 given by Eqs.(17,18) is the plastic ratchet boundary and depends upon the ratio of the two plastic yield strengths, $\alpha$.

For the interpretation with creep we again note that the purely plastic ratchet strains and plastic ratchet boundaries are obtained from (15-18) by putting $\alpha=1$. The result is consistent with the analyses of modified Bree loading in Refs.[3-5], and the expressions are given explicitly in Tables 3 and 4, labelled "plastic ratchet strain" and "plastic ratchet boundary". However the type 1 and type 3 plastic ratchet strains are discontinuous across the "creep hyperbola", (6), being continuous only across the "plastic hyperbola", (7). This motivates the introduction of the intermediate ratchet region of type 3, lying between the two hyperbolae, just as for Bree loading.

We can again identify CR1, CR2, CR3 as the regions in which ratcheting is occurring but would not occur if the behaviour was purely plastic, i.e., with no creep. Consequently the whole of the ratchet strain given by $(15,16)$ may be interpreted as creep ratchet strain in regions CR1, CR2, CR3. In regions R1, R2, R3 the creep ratchet strain follows by subtracting the plastic ratchet strain from the total ratchet strain given by $(15,16)$. The creep and plastic ratchet strains summarised in Table 4 are continuous across all boundaries (as given in Table 3). The region above the plastic ratchet boundaries are denoted R1, R2, R3 on Fig.7 (for the case $\alpha=0.8$ ). Because our analysis necessarily restricts $X$ to a maximum value, $X \leq \alpha$, not all these regions always occur. For example, region $\mathrm{R} 1$ is absent for $\alpha=0.6$, see Fig. 8 .

Fig.9 shows the ratchet boundaries and sub-regions for $\alpha$ values of $0.4,0.5,0.6,0.7,0.8$ and 0.9 , noting that the lower boundaries of the R-regions (plastic ratchet boundaries) are the same in every case. Table 3 summarises the algebraic expressions for the various curves in Fig.9.

Finally, Fig. 10 compares the plastic and creep ratchet boundaries for Bree and modified Bree loading for the case $\alpha=0.6$. As was observed in Refs.[3-5] for plastic ratcheting, the modified Bree loading is substantially less onerous than the original Bree loading also for creep ratcheting.

\section{Confirmation of Analysis Using LMM}

Calculating the steady state response of structures subject to cyclic loading can require a large number of increments in a full step-by-step analysis which becomes computationally expensive. As a result, direct methods have been developed to assess the stabilised response of structures subject to cyclic loading, e.g., Ref.[6]. The LMM method has been extended beyond the range of most other direct methods by including the evaluation of the ratchet limit and also the steady state cyclic behaviour with creep fatigue interaction, see Ref.[9]. Experience with the LMM method is accumulating and the method is proving to be robust, Ref.[10]. Consequently the LMM method has been used to analyse the problems considered analytically in $\$ 2$ and $\S 3$. This may be considered as a verification of the analysis of $\S 2$ and $\S 3$, or as a validation of the LMM code, according to taste.

LMM runs were carried out to locate the shakedown and ratchet boundaries for the case $\alpha=1$ and the ratchet boundaries for the case $\alpha=0.6$. The results for Bree loading are shown in comparison with the analytic results in Fig.11. The dashed curves are from the Bree analysis (shakedown and ratchet boundaries). The continuous curve is the ratchet boundary from the analysis of $\S 2$ for $\alpha=0.6$. The points are the LMM results and show excellent agreement with the analytical results in all cases. The basis of the LMM results are the shakedown bounding theorems of Koiter, Ref.[15], for the upper bounds and of Melan, Ref.[16], for the lower bounds. The former applies an energy balance between 
work done and internal energy dissipation. The latter uses the residual stress generated by the solution to ensure that the yield stress is not violated at any time during the cycle.

The particular version of the LMM code used here finds the level of additional steady loading which can be added before ratcheting occurs. This is not ideal for the case of the modified Bree loading because this involves no steady loading. (Versions of the code to avoid this limitation are in development). However the code can be deployed for this loading by ensuring that the amount of additional steady loading which is required is very small. LMM runs were carried out for modified Bree loading to locate the shakedown and ratchet boundaries for the case $\alpha=1$ and the ratchet boundaries for the case $\alpha=0.6$. The results are shown in Fig.12 (which also indicates the small steady load which was included as explained above). The dashed curves are from the analyses of Refs.[3-5] (shakedown and ratchet boundaries). The continuous curve is the ratchet boundary from the analysis of $\S 3$ for $\alpha=0.6$. The points are the LMM results and again show excellent agreement with the analytical results in all cases.

\section{Conclusion - Assessment of Creep Ratcheting}

Having obtained the creep ratchet strain per cycle, $\varepsilon_{\text {ratchet }}^{c}$, the total creep ratchet strain over $N$ cycles is $N \varepsilon_{\text {ratchet }}^{c}$. The proposal is that the acceptability of this creep ratchet strain can be assessed by comparison with the creep ductility of the material. Various options may be proposed as regards how conservatism should be built into this procedure. One option is to use lower bound proof stress and isochronous creep deformation data, in which case it may be adequate to employ the best estimate creep ductility. Alternatively, best estimate proof stress and isochronous creep deformation data may be used together with the lower bound creep ductility.

This method for assessing creep ratcheting is similar in spirit to that proposed by Carter et al., Ref. [17], being based on elastic perfectly plastic cyclic analysis but without explicit time dependence.

Instead, "time dependence is addressed by specifying a pseudo yield strength that bounds creep strain accumulation by appropriately choosing the time and temperature" (Ref. [17]). However the present paper also presents an explicit, exact, analytic solution of the Bree and modified Bree problems under these conditions.

\section{References}

[1] J.Bree, "Elastic-Plastic Behaviour of Thin Tubes Subject to Internal Pressure and Intermittent High-Heat Fluxes with Application to Fast Nuclear Reactor Fuel Elements", Journal of Strain Analysis (1967) 2, 226-238.

[2] J.Bree, "Plastic Yielding of Thin Tubes Subjected to Internal Pressure and Cyclic Thermal Stresses", Journal of Strain Analysis (1968) 3, 122-127.

[3] H.W.Ng and D.N.Moreton, "Ratchetting rates for a Bree cylinder subjected to in-phase and outof-phase loading", Journal of Strain Analysis for Engineering Design 21 (1986) 1-6

[4] H.W.Ng and D.N.Moreton, "Alternating plasticity at the surfaces of a Bree cylinder subjected to in-phase and out-of-phase loading", Journal of Strain Analysis for Engineering Design 22 (1987) 107-113.

[5] R.A.W.Bradford, "The Bree problem with primary load cycling in-phase with the secondary load", International Journal of Pressure Vessels and Piping 99-100 (2012) 44-50.

[6] ABAQUS analysis User's manual. Dassault Systemes Simulia Corp.; 2010. Version 6.10 ed.

[7] H.F.Chen, A.R.S.Ponter and R.A.Ainsworth, "The Linear Matching Method Applied to the High Temperature Life Integrity of Structures. Part 1. Assessments Involving Constant Residual Stress Fields", International Journal of Pressure Vessels and Piping, 83 (2006) 123-135.

[8] H.F.Chen and A.R.S.Ponter, "Linear Matching Method on the Evaluation of Plastic and Creep Behaviours for Bodies Subjected to Cyclic Thermal and Mechanical Loading", Int.J.Numerical Methods in Engineering, 68 (2006) 13-32. 
[9] H.F.Chen, W.Chen, J.Ure, "Linear matching method on the evaluation of cyclic behaviour with creep effect", Proc. ASME pressure vessels \& piping conf.; PVP2012-78065, Toronto, Canada: ASME; 2012, July 15-19.

[10] Y.Gorash, H.F.Chen, "Creep-fatigue assessment of cruciform weldments using the linear matching method”, International Journal of Pressure Vessels and Piping 104 (2013) 1-13.

[11]H.F.Chen, "Lower and upper bound shakedown analysis of structures with temperaturedependent yield stress", Journal of Pressure Vessel Technology 2010;132(1) p.011202: 1-8.

[12]R5, "Assessment Procedure for the High Temperature Response of Structures", R5 Issue 3, June 2003, EDF Energy. (See also D.W.Dean, P.J.Budden and R.A.Ainsworth, "R5 Procedures for Assessing the High Temperature Response of Structures: Current Status and Future Developments", Proceedings of the 2007 ASME Pressure Vessels and Piping Conference, July 22-26, 2007, San Antonio, Texas, USA, paper PVP2007-26569).

[13] W.J.O'Donnell and J.Porowski, "Upper Bounds for Accumulated Strains due to Creep Ratcheting”, J.Press.Vess.Tech. (Transactions of ASME), 96 (1974) 150-154. Also available within F.A.Leckie, J.C.Gerdeen, V.K.Sazawal, W.J.O’Donnell, J.Porowski and E.Krempl, “A Review of Bounding Techniques in Shakedown and Ratcheting at Elevated Temperatures", Welding Research Council Bulletin 195 (2005).

[14] ASME Boiler and Pressure Vessel Code, Section III, "Rules for Construction of Nuclear Facility Components", Division 1-Subsection NB, "Class 1 Components".

[15] W. T. Koiter, "General theorems for elastic plastic solids," in Progress in solid mechanics, J. Sneddon and R. Hill, Eds. Amsterdam: , 1960, pp. 167-221.

[16]E. Melan, "Theorie statisch unbestimmter systeme aus ideal-plastichem baustoff," Sitzungsber. $d$. Akad. d. Wiss, vol. 145, no. 2A, pp. 195-218, 1936.

[17] Carter P, Jetter RI, Sham T-L. Application of elastic-perfectly plastic cyclic analysis to assessment of creep strain. In: Proceedings of the ASME 2012 pressure vessels \& piping conference, PVP2012 July 15-19, 2012. Toronto, Ontario, Canada. 
Table 1 Ratchet Boundaries and Ratchet Sub-Regions: Bree Loading

\begin{tabular}{|l|l|}
\hline \multicolumn{1}{|c|}{ Boundary Curve (see Figure 4) } & \multicolumn{1}{c|}{ Equation } \\
\hline (1) Creep ratchet boundary, type 1 & $Y=\{\sqrt{(1-X)}+\sqrt{(\alpha-X)}\}^{2}$ \\
\hline (2) Creep ratchet boundary, type 2 & $X Y=\alpha$ \\
\hline (3) Plastic ratchet boundary, type 1 & $Y=4(1-X)$ \\
\hline (4) Plastic ratchet boundary, type 2 & $X Y=1$ \\
\hline (5) "Creep hyperbola" & $Y(\alpha-X)=\alpha^{2}$ \\
\hline (6) "Plastic hyperbola" & $Y(1-X)=1$ \\
\hline Common point of intersection of (1), (2), (5), (6) & $X=\frac{\alpha}{1+\alpha} \quad Y=1+\alpha$ \\
\hline Common point of intersection of (3), (4), (6) & $X=\frac{1}{2} \quad Y=2$ \\
\hline
\end{tabular}

Table 2 Ratchet Strains (Interpreted with Creep), Bree Loading

The total ratchet strain is the sum of the creep and plastic ratchet strains. The algebraic expression for the total ratchet strain is the same in regions $\mathrm{R}$ as in the corresponding region CR. When interpreted without creep this total ratchet strain is all plastic ratchet strain with on-load:off-load yield stress ratio $\alpha$ as in Fig.1.

\begin{tabular}{|c|l|c|c|}
\hline \multicolumn{1}{|c|}{ Ratcheting Region } & \multicolumn{1}{|c|}{$\begin{array}{c}\text { Creep Ratchet } \\
\text { Strain }\left(/ \varepsilon_{y}\right)\end{array}$} & $\begin{array}{c}\text { Plastic Ratchet } \\
\text { Strain }\left(/ \varepsilon_{y}\right)\end{array}$ \\
\hline R1 & $\begin{array}{l}\text { Above } Y=4(1-X) \\
\text { Below } Y(1-X)=1\end{array}$ & $2\{\sqrt{Y(1-X)}-\sqrt{Y(\alpha-X)}\}$ & $2\{Y-2 \sqrt{Y(1-X)}\}$ \\
\hline R2 & $\begin{array}{l}\text { Above } X Y=1 \\
\text { Above } Y(\alpha-X)=\alpha^{2}\end{array}$ & $2(X Y-1)$ \\
\hline R3 & $\begin{array}{l}\text { Above } X Y=1 \\
\text { Above } Y(1-X)=1 \\
\text { Below } Y(\alpha-X)=\alpha^{2}\end{array}$ & $1+Y(1-X)-2 \sqrt{Y(\alpha-X)}+1)$ & $2(X Y-1)$ \\
\hline CR1 & $\begin{array}{l}\text { Above } Y=\{\sqrt{(1-X)}+\sqrt{(\alpha-X)}\}^{2} \\
\text { Below } Y=4(1-X) \\
\text { Below } Y(1-X)=1\end{array}$ & $2\{Y-\sqrt{Y(1-X)}-\sqrt{Y(\alpha-X)}\}$ & 0 \\
\hline CR2 & $\begin{array}{l}\text { Above } X Y=\alpha \\
\text { Below } X Y=1 \\
\text { Above } Y(\alpha-X)=\alpha^{2}\end{array}$ & $X Y+Y-1-2 \sqrt{Y(\alpha-X)}$ & 0 \\
\hline CR3 & $\begin{array}{l}\text { Below } X Y=1 \\
\text { Above } Y(1-X)=1 \\
\text { Below } Y(\alpha-X)=\alpha^{2}\end{array}$ & $\left(\frac{1+\alpha}{\alpha}\right)(X Y-\alpha)$ \\
\hline
\end{tabular}


Table 3

Ratchet Boundaries and Ratchet Sub-Regions: Modified Bree Loading

\begin{tabular}{|l|l|}
\hline \multicolumn{1}{|c|}{ Boundary Curve (see Figure 7) } & \multicolumn{1}{c|}{ Equation } \\
\hline (1) Creep ratchet boundary, type 1 & $\alpha-X=\frac{1}{4 Y}(Y-1)^{2}$ \\
\hline (2) Creep ratchet boundary, type 2 & $X Y=\alpha(\alpha+1)$ \\
\hline (3) Plastic ratchet boundary, type 1 & $1-X=\frac{1}{4 Y}(Y-1)^{2}$ \\
\hline (4) Plastic ratchet boundary, type 2 & $X Y=2$ \\
\hline (5) "Creep hyperbola" & $Y(\alpha-X)=\alpha^{2}$ \\
\hline (6) "Plastic hyperbola" & $Y(1-X)=1$ \\
\hline Common point of intersection of (1), (2), (5) & $X=\frac{\alpha(1+\alpha)}{1+2 \alpha} \quad Y=1+2 \alpha$ \\
\hline Common point of intersection of (3), (4), (6) & $X=\frac{2}{3}$ \\
\hline
\end{tabular}

Table 4 Ratchet Strains (Interpreted with Creep), Modified Bree Loading

The total ratchet strain is the sum of the creep and plastic ratchet strains. The algebraic expression for the total ratchet strain is the same in regions $\mathrm{R}$ as in the corresponding region CR. When interpreted without creep this total ratchet strain is all plastic ratchet strain with on-load:off-load yield stress ratio $\alpha$ as in Fig.1.

\begin{tabular}{|c|c|c|c|}
\hline \multicolumn{2}{|r|}{ Ratcheting Region } & $\begin{array}{l}\text { Creep Ratchet } \\
\text { Strain }\left(/ \varepsilon_{y}\right)\end{array}$ & $\begin{array}{l}\text { Plastic Ratchet } \\
\text { Strain }\left(/ \varepsilon_{y}\right)\end{array}$ \\
\hline $\mathrm{R} 1$ & $\begin{array}{l}\text { Above } 1-X=\frac{1}{4}(Y-1)\left(1-\frac{1}{Y}\right) \\
\text { Below } Y(1-X)=1\end{array}$ & $2\{\sqrt{Y(1-X)}-\sqrt{Y(\alpha-X)}\}$ & $Y-1-2 \sqrt{Y(1-X)}$ \\
\hline $\mathrm{R} 2$ & $\begin{array}{l}\text { Above } X Y=2 \\
\text { Above } Y(\alpha-X)=\alpha^{2}\end{array}$ & $(1-\alpha)\left(\frac{X Y}{\alpha}+1\right)$ & $X Y-2$ \\
\hline $\mathrm{R} 3$ & $\begin{array}{l}\text { Above } X Y=2 \\
\text { Above } Y(1-X)=1 \\
\text { Below } Y(\alpha-X)=\alpha^{2}\end{array}$ & $1+Y(1-X)-2 \sqrt{Y(\alpha-X)}$ & $X Y-2$ \\
\hline CR1 & $\begin{array}{l}\text { Above } \alpha-X=\frac{1}{4}(Y-1)\left(1-\frac{1}{Y}\right) \\
\text { Below } 1-X=\frac{1}{4}(Y-1)\left(1-\frac{1}{Y}\right) \\
\text { Below } Y(1-X)=1\end{array}$ & $Y-1-2 \sqrt{Y(\alpha-X)}$ & 0 \\
\hline $\mathrm{CR} 2$ & $\begin{array}{l}\text { Above } X Y=\alpha(\alpha+1) \\
\text { Below } X Y=2 \\
\text { Above } Y(\alpha-X)=\alpha^{2}\end{array}$ & $\frac{X Y}{\alpha}-(1+\alpha)$ & 0 \\
\hline CR3 & $\begin{array}{l}\text { Below } X Y=2 \\
\text { Above } \alpha-X=\frac{1}{4}(Y-1)\left(1-\frac{1}{Y}\right) \\
\text { Above } Y(1-X)=1 \\
\text { Below } Y(\alpha-X)=\alpha^{2}\end{array}$ & $Y-1-2 \sqrt{Y(\alpha-X)}$ & 0 \\
\hline
\end{tabular}




\section{Figure 1 The Idealised Elastic-Perfectly Plastic Stress-Strain Curves}

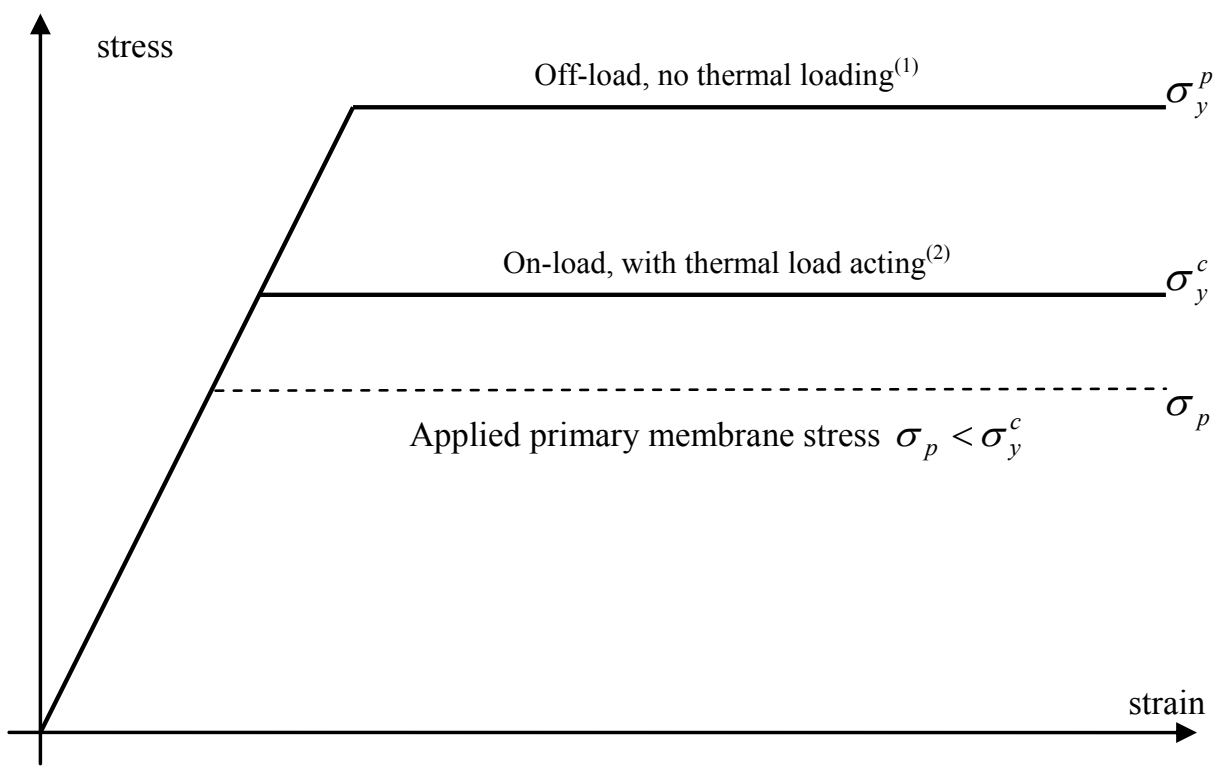

\footnotetext{
${ }^{(1)}$ When interpreted with creep $\sigma_{y}^{p}$ is the

${ }^{(2)}$ When interpreted with creep $\sigma_{y}^{c}$ is the stress smallest $0.2 \%$ proof stress between offload and on-load temperatures, possibly multiplied by a shakedown factor $\mathrm{K}_{\mathrm{S}}$ giving an isochronous inelastic strain of $0.2 \%$ over one creep dwell, possibly multiplied by a shakedown factor $\mathrm{K}_{\mathrm{S}}$
} 
Figure 2 Stress Distributions Which Can Lead to Ratcheting (R1/CR1)

Plasticity on One Surface Only at Each Load Condition

Bree Loading. NOT TO SCALE - SCHEMATIC ONLY

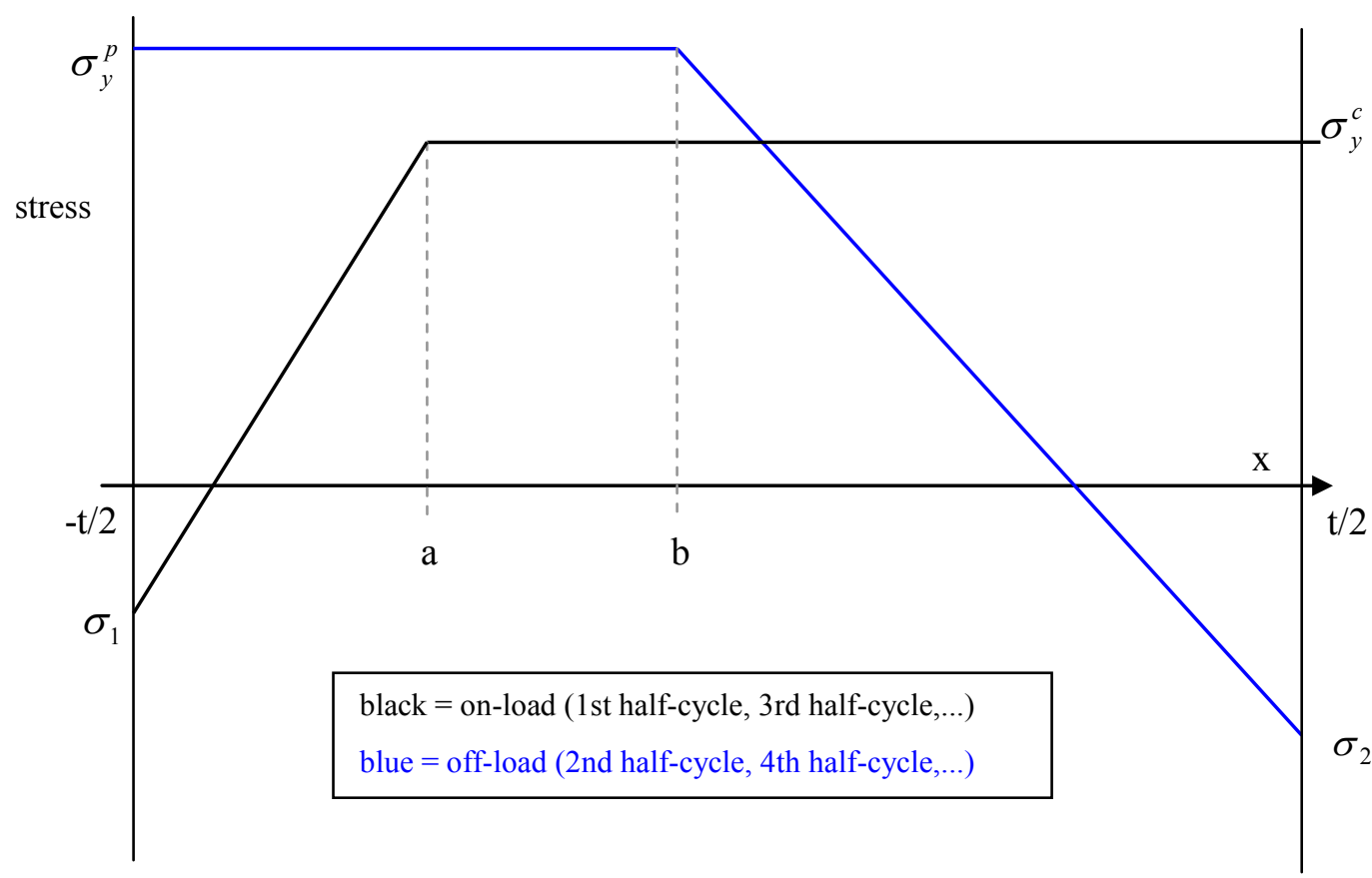

Figure 3 Stress Distributions Which Can Lead to Ratcheting (R2/CR2)

Plasticity on Both Surfaces at Both Load Conditions

Bree Loading. NOT TO SCALE - SCHEMATIC ONLY

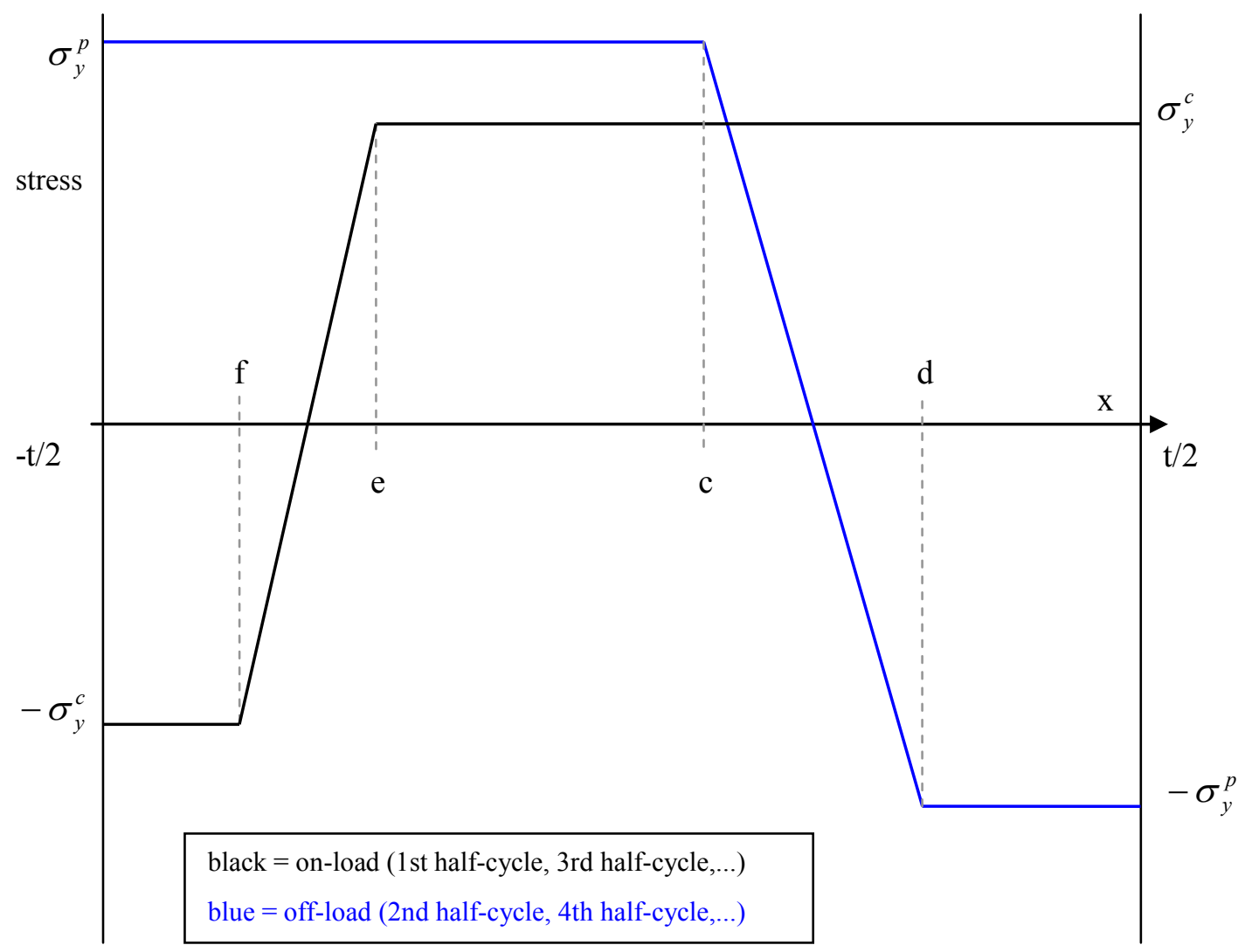


Figure 4 Ratchet Regions Illustrated for Bree Loading and $\alpha=0.6$

$\mathrm{R} 1, \mathrm{R} 2, \mathrm{R3}=$ plastic and creep ratcheting; $\mathrm{CR} 1, \mathrm{CR2}, \mathrm{CR3}=$ creep ratcheting only

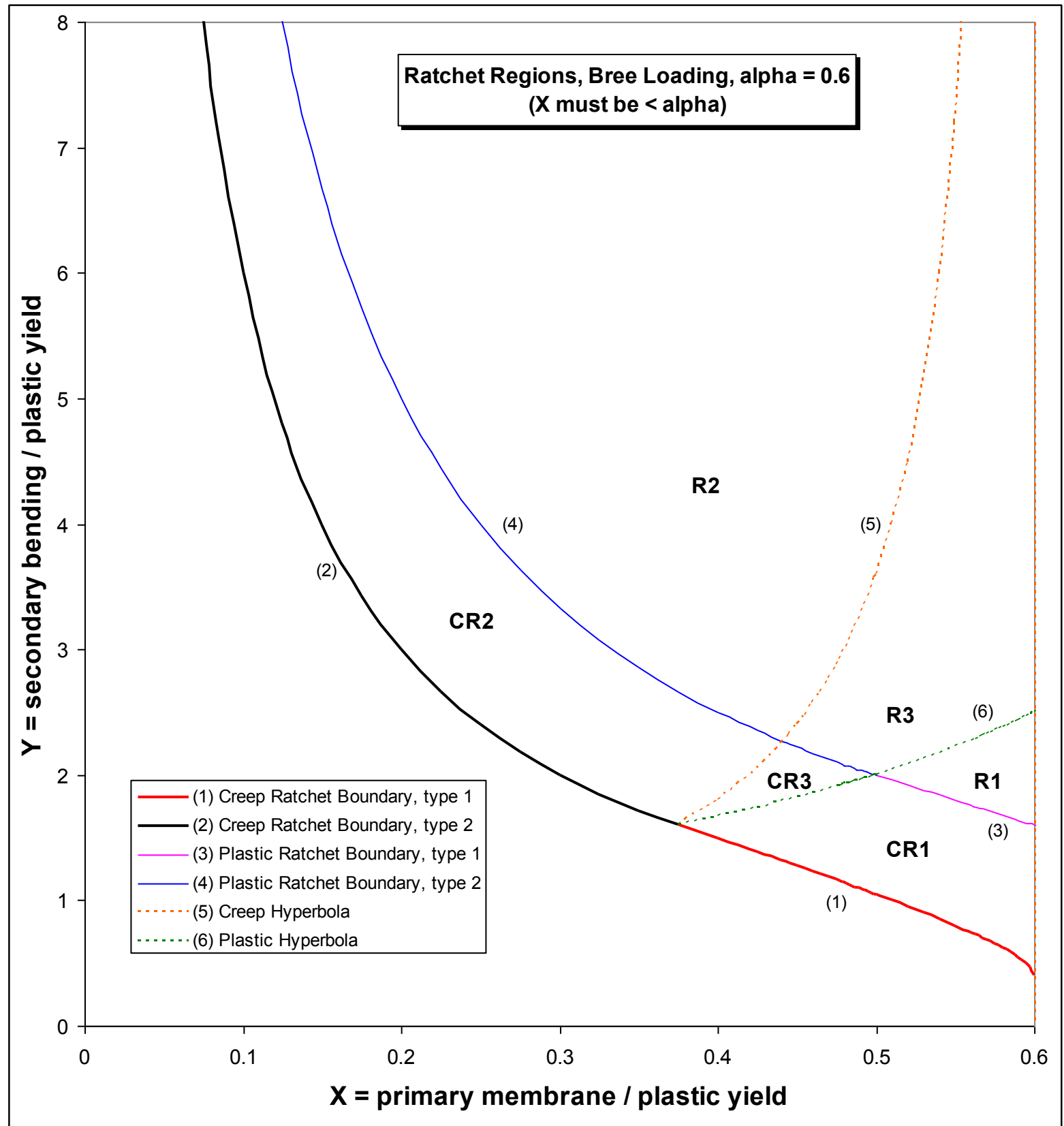


Figure 5 Ratchet Boundaries for Bree Loading and Various $\alpha$

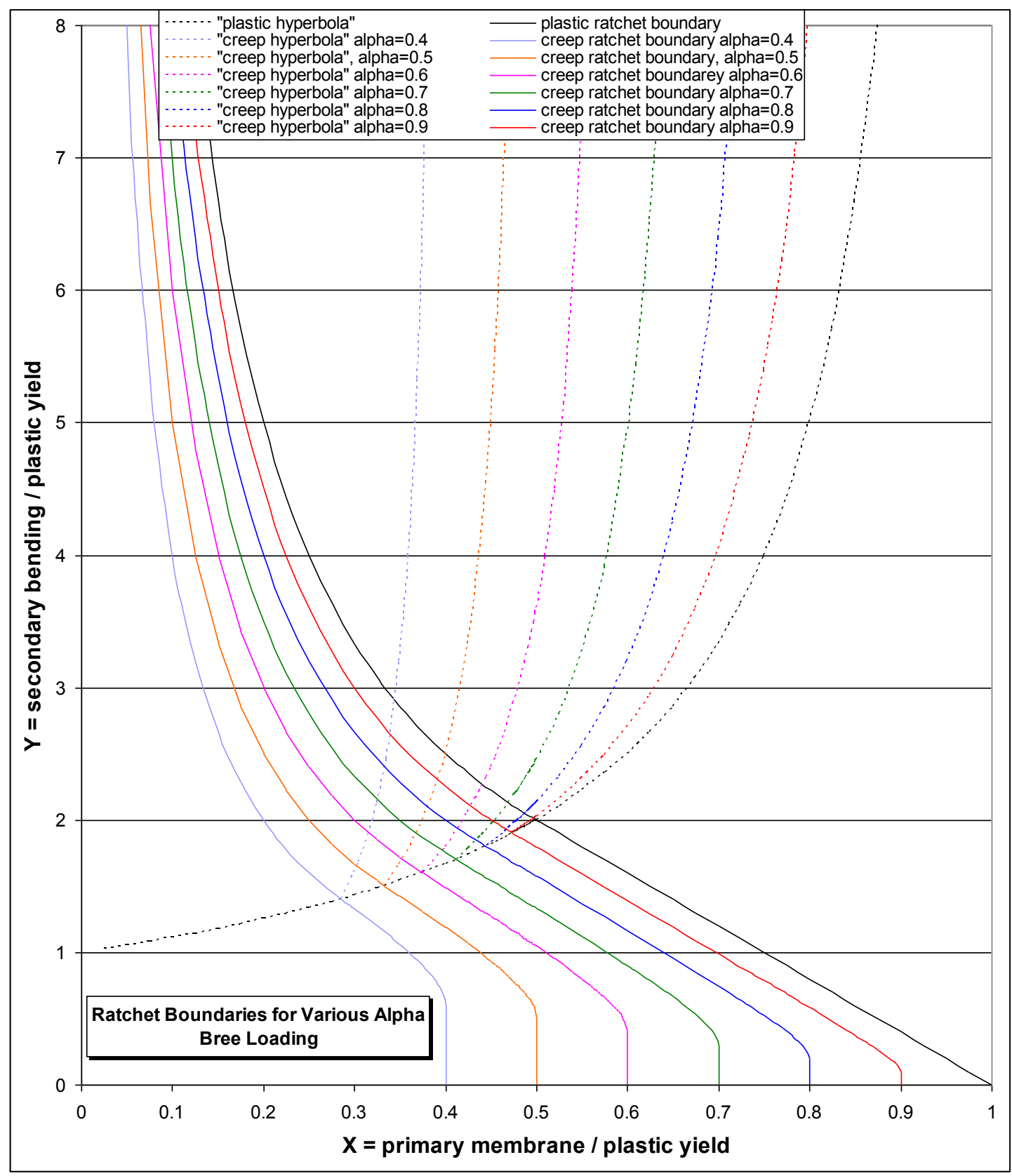


Figure 6 Stress Distributions Which Can Lead to Ratcheting (R1/CR1)

Plasticity on One Surface Only when at Power

Modified Bree Loading. NOT TO SCALE - SCHEMATIC ONLY

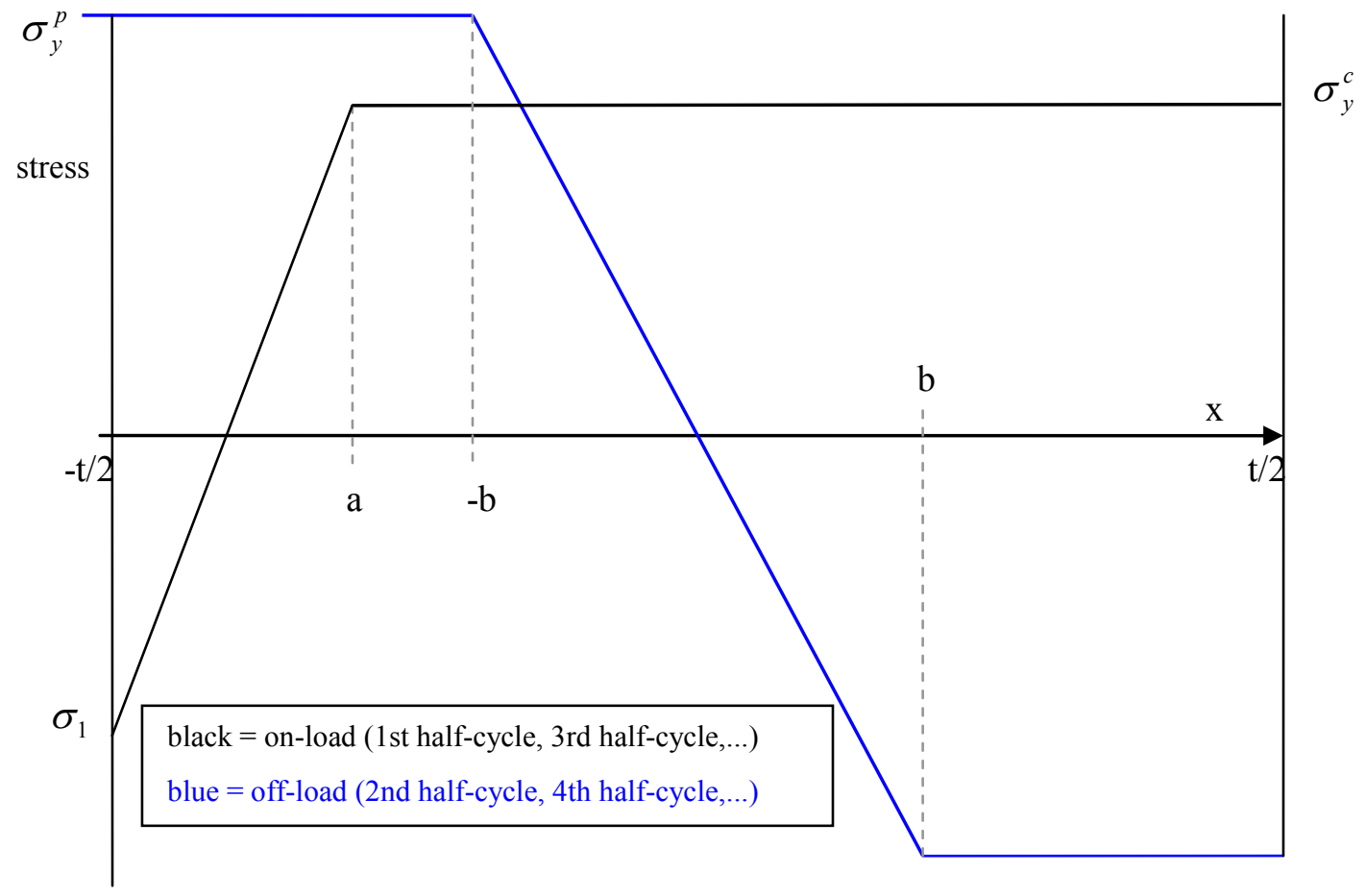


Figure 7 Ratchet Regions Illustrated for Modified Bree Loading and $\alpha=0.8$

$\mathrm{R} 1, \mathrm{R} 2, \mathrm{R} 3$ = plastic and creep ratcheting; $\mathrm{CR} 1, \mathrm{CR} 2, \mathrm{CR3}=$ creep ratcheting only

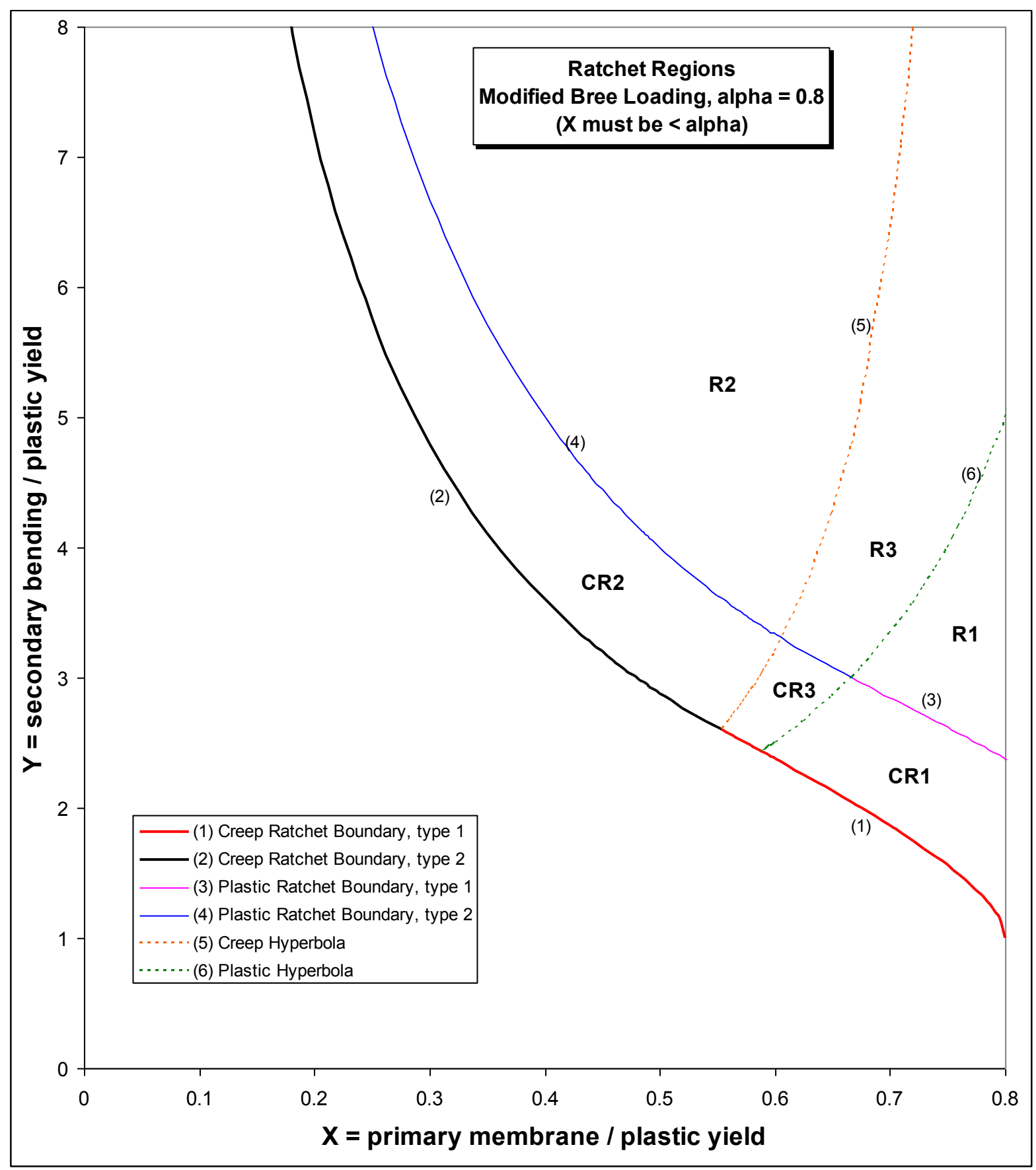


Figure 8 Ratchet Regions Illustrated for Modified Bree Loading and $\alpha=0.6$

$\mathrm{R2,R3}=$ plastic and creep ratcheting; CR1,CR2,CR3 = creep ratcheting only

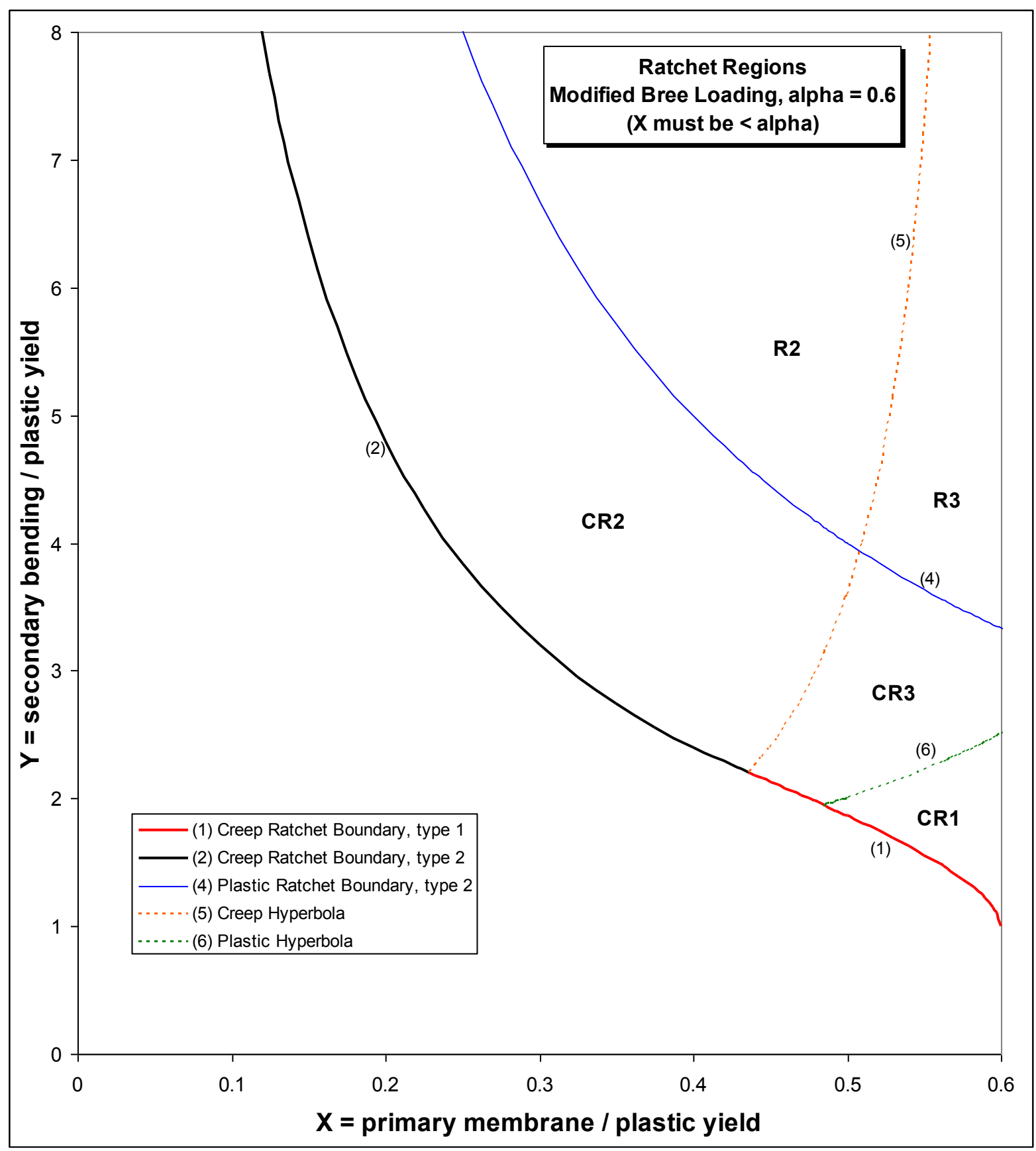


Figure 9 Ratchet Boundaries for Modified Bree Loading and Various $\alpha$

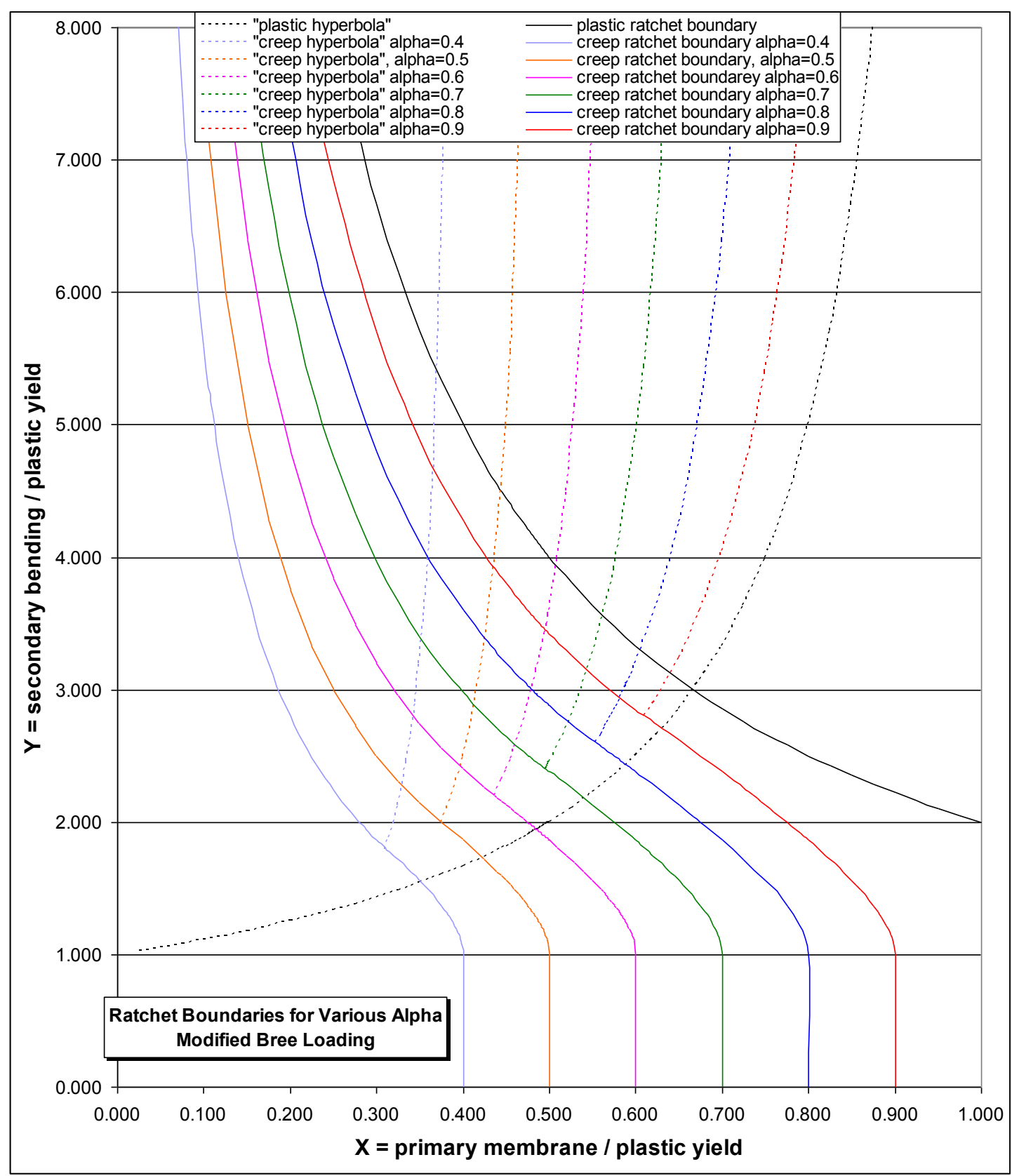




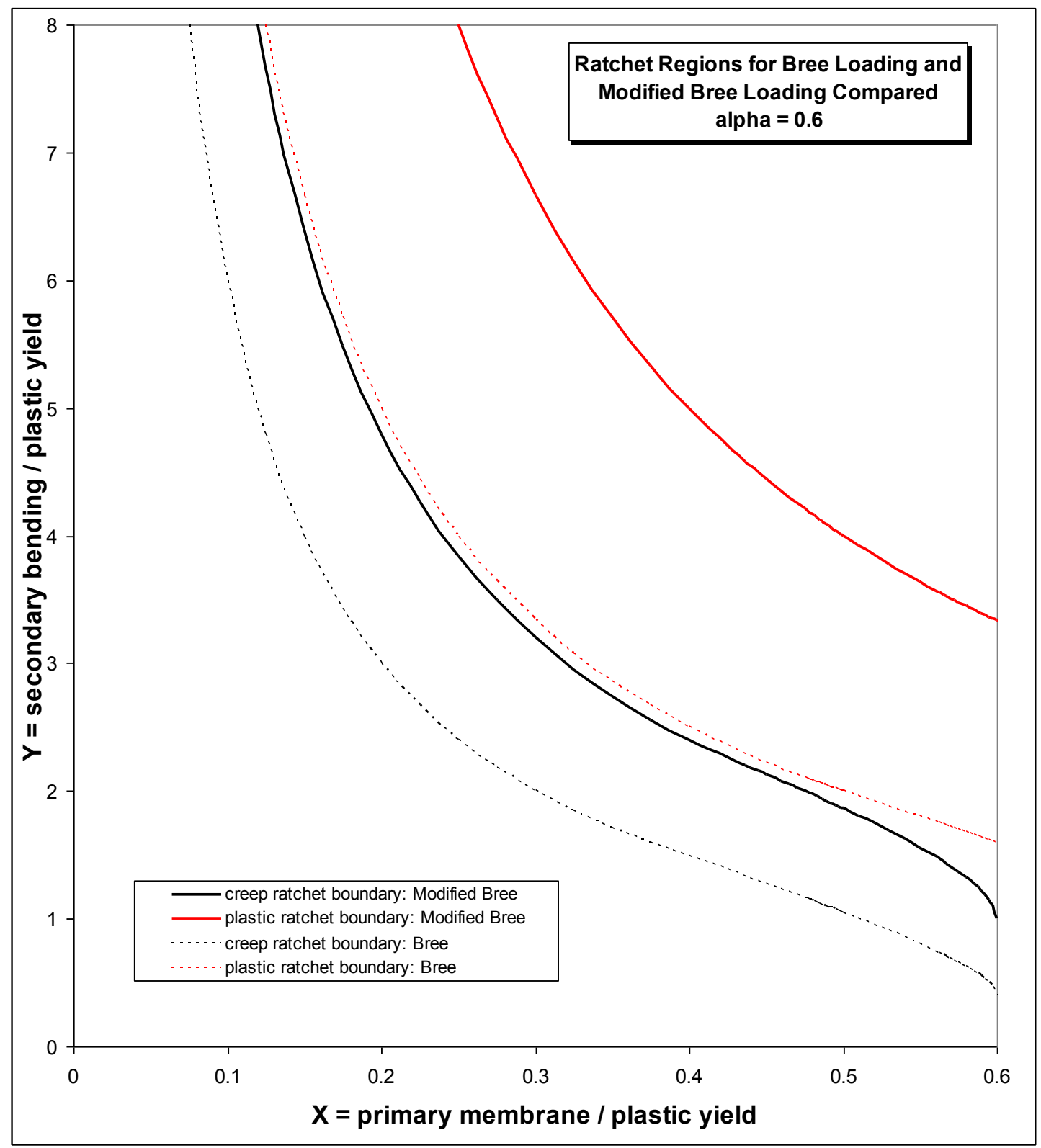


Figure 11

Analytic Ratcheting Boundaries Compared With LMM Derivation: Bree Loading

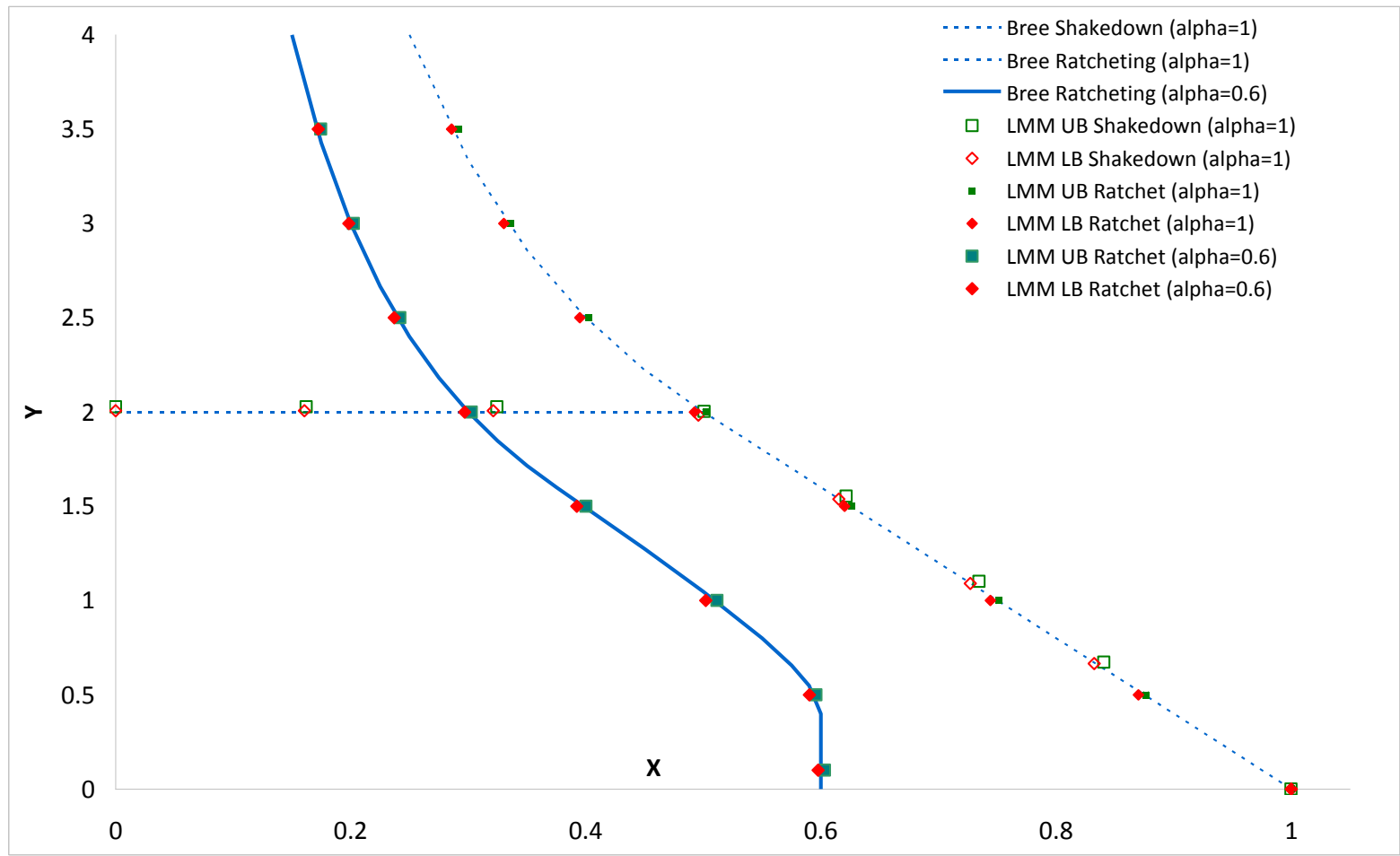

Figure 12 Analytic Ratcheting Boundaries Compared With LMM Derivation: Modified Bree Loading

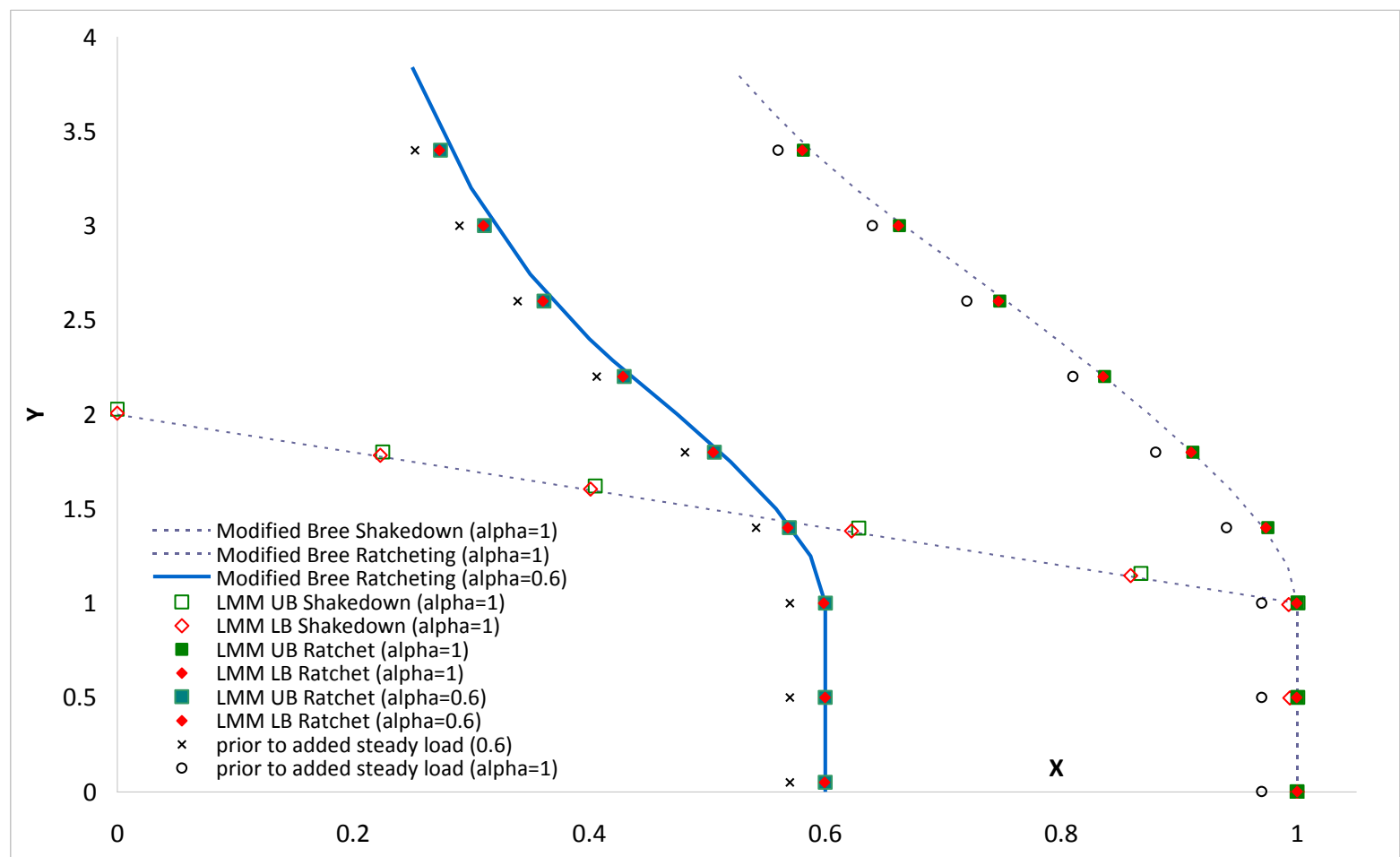

